\title{
Geo-Spatial Approach for Urban Green Space and Environmental Quality Assessment: A Case Study in Addis Ababa City
}

\author{
Roza Assaye1 ${ }^{1}$, K. V. Suryabhagavan ${ }^{*}$, M. Balakrishnan ${ }^{2}$, S. Hameed ${ }^{3}$ \\ ${ }^{1}$ School of Earth Sciences, Addis Ababa University, Addis Ababa, Ethiopia \\ ${ }^{2}$ Department of Zoological Sciences, Addis Ababa University, Addis Ababa, Ethiopia \\ ${ }^{3}$ College of Science, Sultan Qaboos University, Muscat, Oman \\ Email: *drsuryabhagavan@gmail.com
}

How to cite this paper: Assaye, R., Suryabhagavan, K.V., Balakrishnan, M. and Hameed, S. (2017) Geo-Spatial Approach for Urban Green Space and Environmental Quality Assessment: A Case Study in Addis Ababa City. Journal of Geographic Information System, 9, 191-206. https://doi.org/10.4236/jgis.2017.92012

Received: December 15, 2016

Accepted: April 27, 2017

Published: April 30, 2017

Copyright $\odot 2017$ by authors and Scientific Research Publishing Inc. This work is licensed under the Creative Commons Attribution International License (CC BY 4.0).

http://creativecommons.org/licenses/by/4.0/

\begin{abstract}
Depending on the rapid growth in infrastructural developments along with the increasing of human population, quality of cities is being deteriorated globally. Assurance of environmental quality is essential for urban planning and developments. This paper presents the potential application of urban green areas as an indicator of urban environmental quality in Addis Ababa, Ethiopia based on indicators of natural parameters extracted from remotely sensed images, and socio-economic variables derived from census data. Physical environmental variables such as land-use/land-cover data, surface temperature, normalized difference vegetation index, and transformed remote sensing variables derived from three landsat images of 1986, 2000 and 2015 were analyzed for the present study. Socio-economic variables including population density and greenhouse gas emission in 2012 were used. Regression analysis, factor analysis and overlay analysis were performed after the two groups of variables were integrated. Four factors such as greenness, crowd, heat island and greenhouse gas emission were used for interpretation. By assigning different weights to each of these factors and proportion of green areas, land-use/land-cover map, environmental risk map and environmental quality index map were generated. The results show deterioration of environmental quality in the study area. It is recommended that future studies should include more parameters to provide a holistic view of the changes in greenness of the city and to try to mitigate adverse effects of development activities leading to human density and depletion of green area in the city.
\end{abstract}

\section{Keywords}

GIS, Landsat, NDVI, Spatiotemporal Distribution, Urban Green Space 


\section{Introduction}

Urban environment quality in the developing part of the world is deteriorating day by day. Large cities are reaching human saturation levels, and are unable to cope up with diverse types of human-induced pressures [1] [2]. Greenery is one of the important ingredients for urban planning with a sustainable environmental quality. Urban environmental quality is based on social, economic, cultural, physical and emotional indices [3]. Urban green spaces and vegetation cover play major roles in balancing human biophysical interconnections and in keeping environmental quality. Green space is a basic requirement of any city that makes tremendous contributions aesthetically and ecologically to the city dwellers for better quality of life [4].

Urban greenery is defined as the overall extent of outdoor space with vegetation cover of trees, bushes, ornamental plants, or grass. Examples of such spaces are squares, parks, rows of trees on road sides, groves, and planted spaces in yards of public or private buildings [5]. Parks and open spaces provide greater diversity of green spaces with positive effects on environmental quality in many megacities around the world [6] [7]. Green space is an important part of urban ecosystems that provides environmental, esthetic, recreational and economic benefits to the urban dwellers. Vegetation provides sufficient oxygen through photosynthesis, pleasing temperatures, cooling through shading and enhanced evapotranspiration [8]. The existence of urban green area in a contemporary urban environment is expected to improve air quality, reduce noise and air pollution and enhances aesthetic quality. Development of urban greenery is a key factor of the overall city planning, as its benefits have direct effects on the environment as well as on the quality of life of its residents. Due to its multi-dimensional, multifaceted and multidisciplinary nature, only one indicator alone cannot measure environmental quality. It requires the integration of a variety of elements such as greenery, built up area, carbon emission, temperature, humidity, waste disposal, accessibility to major roads and population density [9]. However, a major challenge in urban environmental quality is the limit to model and to predict the interactions of all these variables.

The integrated framework of Remote Sensing (RS) and Geographical Information System (GIS) techniques greatly reduces time, effort and expenses in using geographical data. Remote sensing with its advantages of spatial, spectral and temporal availability of data coverage of large and inaccessible areas within a short time has become a handy tool in assessing, monitoring and conserving urban greenery [10]. Satellite Remote Sensing, with its repetitive coverage together with multi-spectral scanner (MSS) capabilities is a powerful tool to map and monitor changes in the areas of analysis [11]. Satellite images enable us to better understand some of the intrinsic components of the ecosystem and the interactions within the whole environment. The relevance of remote sensing monitoring in urban environmental quality is further enhanced by GIS, which makes it possible to integrate remote sensing data with socio-economic variables and in situ data [3] [12]. 
In this research, distribution of urban green area and vegetation density were analysed as the major index for air freshening, which generally improves the urban environmental quality. Building density, population density, temperature, humidity, waste deposal, accessibility to major roads and carbon emission were considered as major indices of degradation of city environment. Understanding the causal factors is a prerequisite to assess and maintain sustainable urban environmental quality. The objectives of the present study were to map the urban green space and evaluate environmental quality of the ten sub-sites of Addis Ababa using natural and social parameters, derived from remote sensing satellite imagery and secondary data.

\section{Study Area and Methods}

\subsection{The Study Area}

Addis Ababa, the capital city of Ethiopia, is one of the largest urban centers in the Sub-Saharan Africa. It is located between latitudes $8^{\circ} 49^{\prime} \mathrm{N}-9^{\circ} 5^{\prime} \mathrm{N}$ and longitudes $38^{\circ} 38^{\prime} \mathrm{E}-38^{\circ} 54^{\prime} \mathrm{E}$, covering a total area of $51,957.92$ ha (Figure 1). Altitudinal zones of Addis Ababa range from $2054 \mathrm{~m}$ to $3023 \mathrm{~m}$ asl., situated in the foothills of the Entoto Mountains, spread across many wooded hillsides and gullies, cut through with fast flowing streams. At present, the city is divided

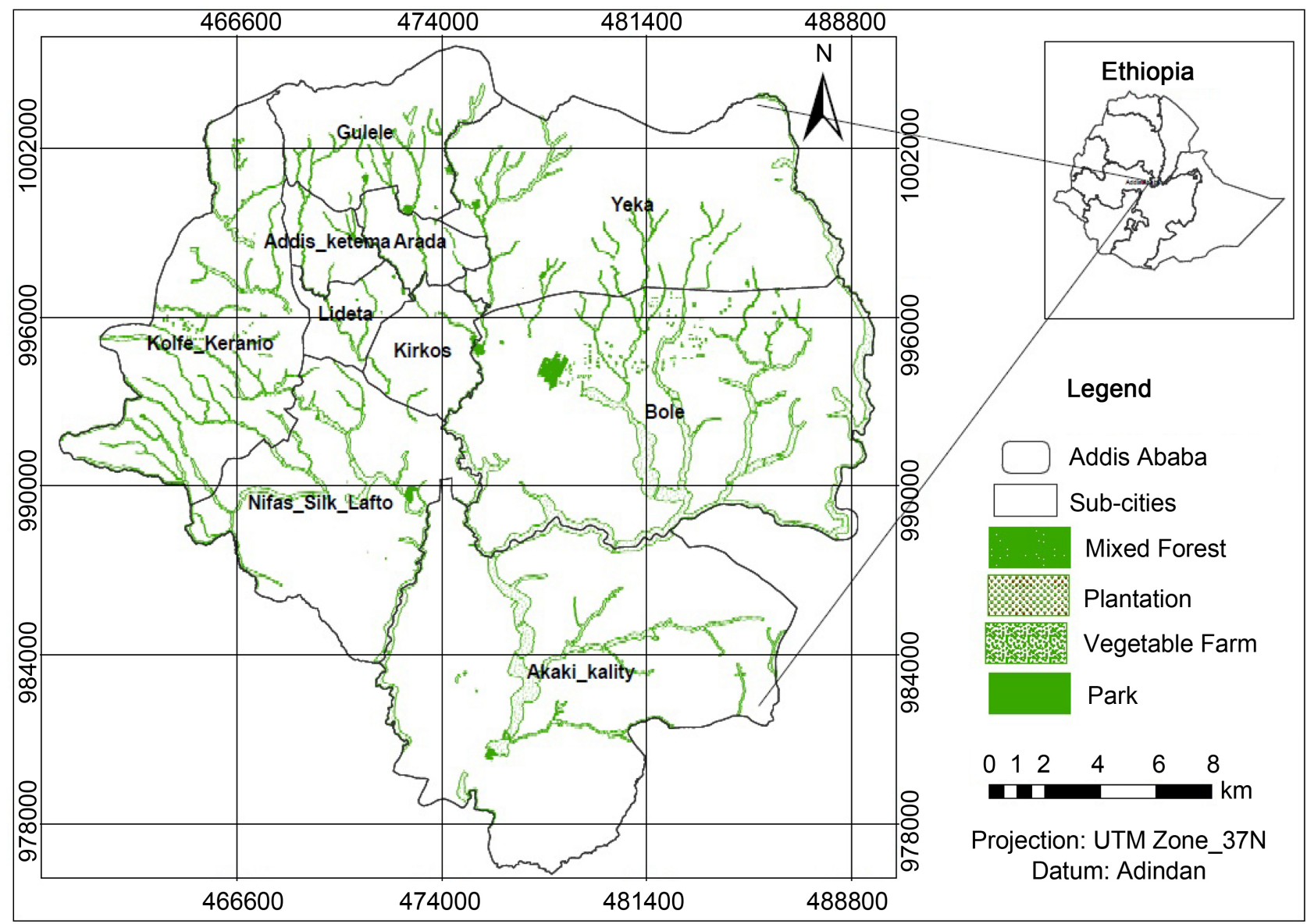

Figure 1. Location map of Addis Ababa. 
in to 10 sub-cities and 116 woredas (administrative districts). Long-term mean annual maximum and minimum temperatures of the city are $24.4^{\circ} \mathrm{C}$ and $7.2^{\circ} \mathrm{C}$, respectively. The total population of Addis Ababa is 3,275,348, which is about $60 \%$ of the total urban population in Ethiopia [13].

\subsection{Methodology}

The data sources for this research primarily came from Landsat images. Secondary data were from National Meteorology Agency of Ethiopia, Central Statistical Agency and Addis Ababa Environmental Protection Authority. The population census data were collected from Central Statistical Agency. The three Landsat images included TM 1986, Landsat 2000 and ETM+ 2015. All images were georectified to a common UTM coordinate system. For the image, 250 ground control points were selected to generate coefficients for a first-order polynomial, and a nearest-neighbor method was applied to resample the image according to their original theoretical spatial resolution. The distribution and quantity of land-use/land-cover patterns, distribution and density of vegetation cover Normalized Difference Vegetation Index (NDVI), surface temperature, greenhouse gas emission, built up density and population density were measured, evaluated and compared for each of the sub-cities in Addis Ababa. Figure 2 shows the general methodology flowchart of the present study.

\subsubsection{Normalized Difference Vegetation Index}

Normalized Difference Vegetation Index was applied for measurement of vegetation distribution and density. Vegetation has a high reflectance in the Near Infrared Red (NIR) bands of a sensor system because of the internal reflectance by the spongy mesophyll tissue of green leaves [14]. The NDVI separates soil vegetation from other ground cover. Its ratio was calculated through the difference of near infra-red (NIR) and red band (RED), which was normalized by summing up these two bands using Equation (1) [15]:

$$
\mathrm{NDVI}=\frac{(\mathrm{NIR}-\mathrm{R})}{(\mathrm{NIR}+\mathrm{R})}
$$

\subsubsection{Surface Temperature Extraction}

The thermal bands of Landsat 8 band 10 and 11 were converted to radiance by calculating the satellite temperature. The satellite temperature was corrected using the emissivity values computed from the NDVI and the satellite temperature was changed to the surface temperature. Basically, the following three steps were involved in the procedure: first, converting the digital number (DN) values of the thermal band into spectral radiance; second, converting the spectral radiance to at satellite brightness temperature, viz., blackbody temperature; and third, adjusting the blackbody temperature to land surface temperature by incorporating emissivity biases due to land-cover differences.

1) Conversion of DN Values to Radiance

Operational land imager (OLI) and Thermal Infrared Sensor (TIRS) band data 


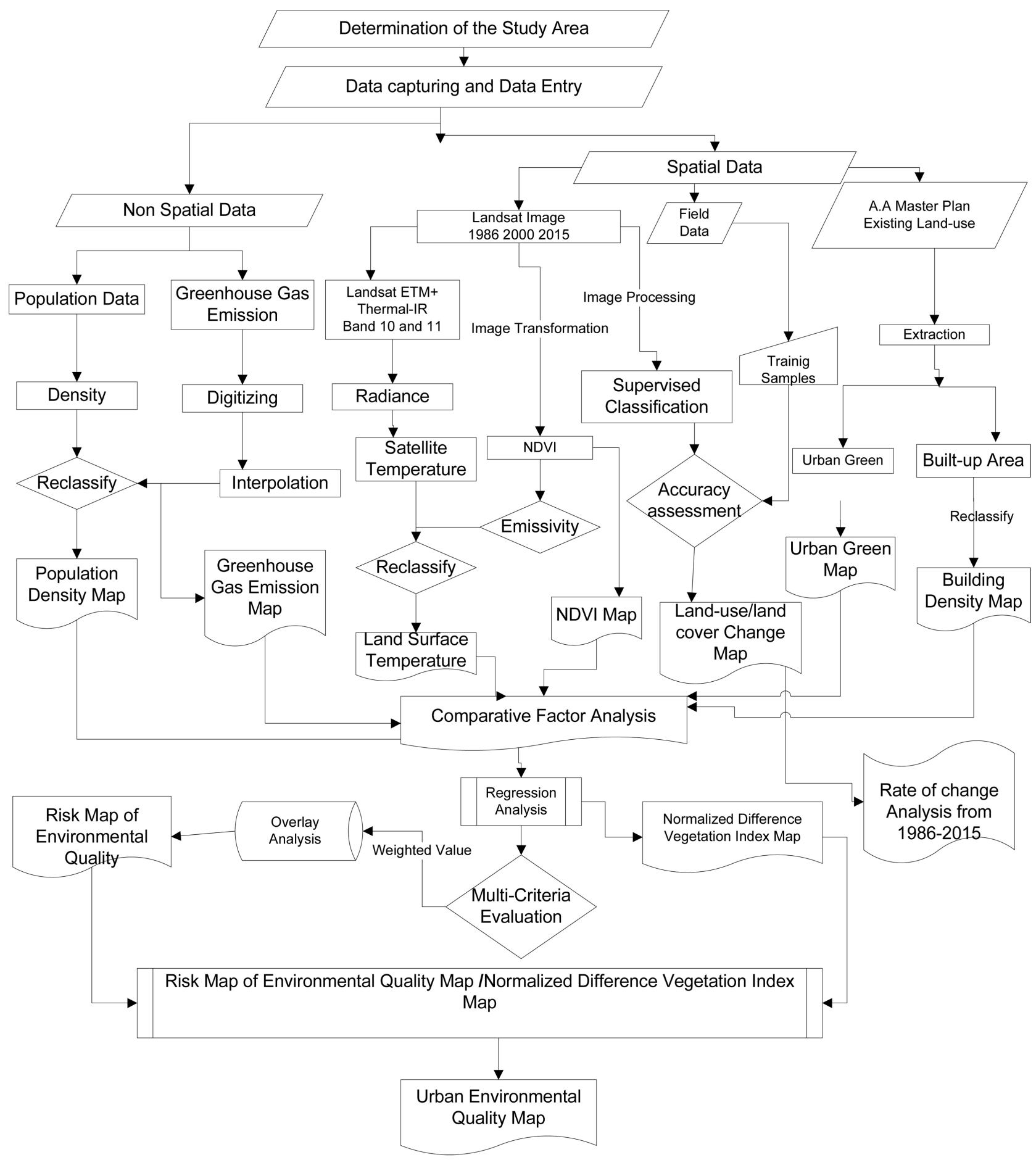

Figure 2. Flow chart of general methodology.

were converted to Top-Of-Atmosphere (TOA) special radiance rescaling factors provided in the metadata file. The first step was conversion of the DN value to the radiance units using Equation (2).

$$
L_{\lambda}=M_{L} * Q_{c a l}+A_{L}
$$

where, $L_{\lambda}$ is the TOA special Radiance (watts $\left./\left(\mathrm{m}^{2} \operatorname{srad} \mu \mathrm{m}\right)\right), M_{L}$ is the Band specific multiplicative rescaling factor from metadata (Radiance_Mult_Band_x 
where $\mathrm{x}$ is band number), $A_{L}$ is the Band specific additive rescaling factor from metadata (Radiance_Add_Band_x where $\mathrm{x}$ is band number) and $Q_{c a l}$ is the Quantized calibrated pixel value in DNs.

2) Conversion of Radiance to at Satellite Temperature

The next step during quantitative analysis was conversion of radiance to temperature. The satellite temperature was calculated under an assumption of unity emissivity using pre-launch calibration constants $K_{1}$ and $K_{2}$ by the following Equation (3):

$$
T=\frac{K_{2}}{\ln \left[\frac{K_{1}}{L_{\lambda}}+1\right]}
$$

where, $T$ is the satellite brightness tempreture (K), $K_{2}$ is the calibration constant $(\mathrm{K})$ and $K_{1}$ is the calibration constant $\left(\mathrm{W} / \mathrm{m}^{2} \mathrm{sr} \mu \mathrm{m}\right)$.

3) Land Surface Temperature

Land surface temperature was computed from calculated emissivity values and calculated temperature at satellite using the following Equation (4):

$$
T_{L S T}=\frac{T_{B}}{1+W *\left(T_{B} / \rho\right) * \ln \varepsilon}
$$

where, $T_{L S T} \rightarrow$ Surface temperature $(\mathrm{K}), T_{B}=$ at satellite temprature, $W$ is the wavelength of emitted radiance (11.45 $\mu \mathrm{m}), \rho=h^{*} c l k\left(1.438 \times 10^{-2} \mathrm{~m} \cdot \mathrm{k}\right)$ with $\sigma=$ stefan Boltzmann constant $\left(1.38 \times 10^{-23} \mathrm{~J} / \mathrm{K}\right), h$ is the plank's constant $(6.26 \times$ $\left.10^{-34} \mathrm{~J} \cdot \mathrm{s}\right)$ and $c$ is the velocity of light $\left(2.998 \times 10^{-8} \mathrm{~m} / \mathrm{s}\right)$.

\subsubsection{Regression and Factor Analysis}

All the five parameters extracted from the physical and secondary datasets were first entered to run ordinary list square correlation analysis. To shed some light on their qualification on the study, Coefficients have the expected sign, statistically significant, no redundancy among explanatory variables, residuals are normally distributed, residuals are not spatially auto-correlated and strong adjusted $r$-squared value summarizes their correlation with all the variables that have been evaluated. For land-use/land-cover, the following methods of data analyses were adopted for the study using Maximum Likelihood classification, accuracy assessment with 250 reference points calculation of the area in hectares of the land-use/land-cover types obtained for each study year and subsequently comparing the results and finally annual rate of change (ha/year) $=(\%$ of recent land-use/land-cover change $-\%$ of previous land-use/land-cover change) $/ 100$ * \# (15 years).

\subsubsection{Overlay Analysis}

Overlay Analysis tools included in the spatial analyst extension commonly used to solve multi-criteria problems such as optimal site selection or suitability modeling. It is a technique for applying a common scale of values to diverse and dissimilar inputs to create an integrated analysis [16] to address which locations are 
most exposed to environmental degradation. The first step was to model operators using ordinary least squares linear regression to generate prediction to model a dependent variable in terms of its relationships to a set of explanatory variable. Then to generate risk-map of environmental quality, parameter layers were computed by reclassifying as population density, building density, urban heat, greenhouse gas density and land-use/land-cover classification. The overall accuracy for land-use/land-cover of 1986 image classification was $88.80 \%$, of 2000 was $85 \%$ and of 2015 was $84.00 \%$. All data groups summarizes as per priority classes, points and influence (weight) values used for weighted overlay to come up with the final environmental risk map of the study area, to show the level of environmental quality of the study area. According to this index, the regions with high greenhouse gas emission, overpopulated, high building density, high heat intensity and low vegetation cover area would get the lowest values, and they will be considered as critical areas. Sparsely populated, low heat, less built-up, low greenhouse gas emission and high vegetation cover areas are considered as environmentally suitable areas.

\section{Results}

\subsection{Findings from Regression Analysis}

Table 1 summarizes the correlation with all the variables that have been evaluated. The correlation coefficients inversely correlated with the dependent variable for most of the tested factors. Probability and robust probability asterisk $\left({ }^{*}\right)$ indicate a coefficient is statistically significant $(\mathrm{p}<0.01)$. Large variance inflation factor (VIF) values ( $>7.5)$ indicate redundancy among the explanatory variables. While there was inflation between population (14) and building (17), variable with a VIF $>7.5$ have removed by one. The R-squared measure of model fit/performance values showed $92 \%$.

\subsection{Findings from Factor Analysis}

The results of 1986, 2000 and 2015 classified images are presented in Figure 3. The results show thick vegetation, cropland and bareland have declined whereas the area of settlement has shown increase in extent (Table 2). From the landuse/land-cover distribution of the year 1986, 2000 and 2015, a total of 51,957.92 ha of thick vegetation/forest land had declined from the initial 11,040.5 ha in 1985 to 5238.90 ha in 2000 and 2730.42 in 2015. Urban cropland/grassland extent

Table 1. Summary of the results of urban environmental quality regression analysis.

\begin{tabular}{ccccccc}
\hline Variable & Coefficient & t-Statistic & Probability & Robust-t & Robust-Pr [b] & VIF [c] \\
\hline Intercept & 0.31966 & 4.195808 & $0.005943^{*}$ & 7.353267 & $0.000393^{*}$ & - \\
Population & -3.038025 & -8.255098 & $0.000132^{*}$ & -10.294585 & $0.000002^{*}$ & 1.923088 \\
Temperature & -0.006742 & -2.649933 & 0.037747 & -4.367938 & 0.004997 & 1.463664 \\
Greenhouse & 0.000027 & 2.722399 & 0.034257 & 4.62643 & 0.003897 & 2.416063 \\
\hline
\end{tabular}

Note: ${ }^{*}$ indicate probability (b) and Robust-pr (b) variable correlation is significant $(\mathrm{P}<0.01)$. 
Table 2. Land-use/land-cover distribution of the year 1986, 2000 and 2015.

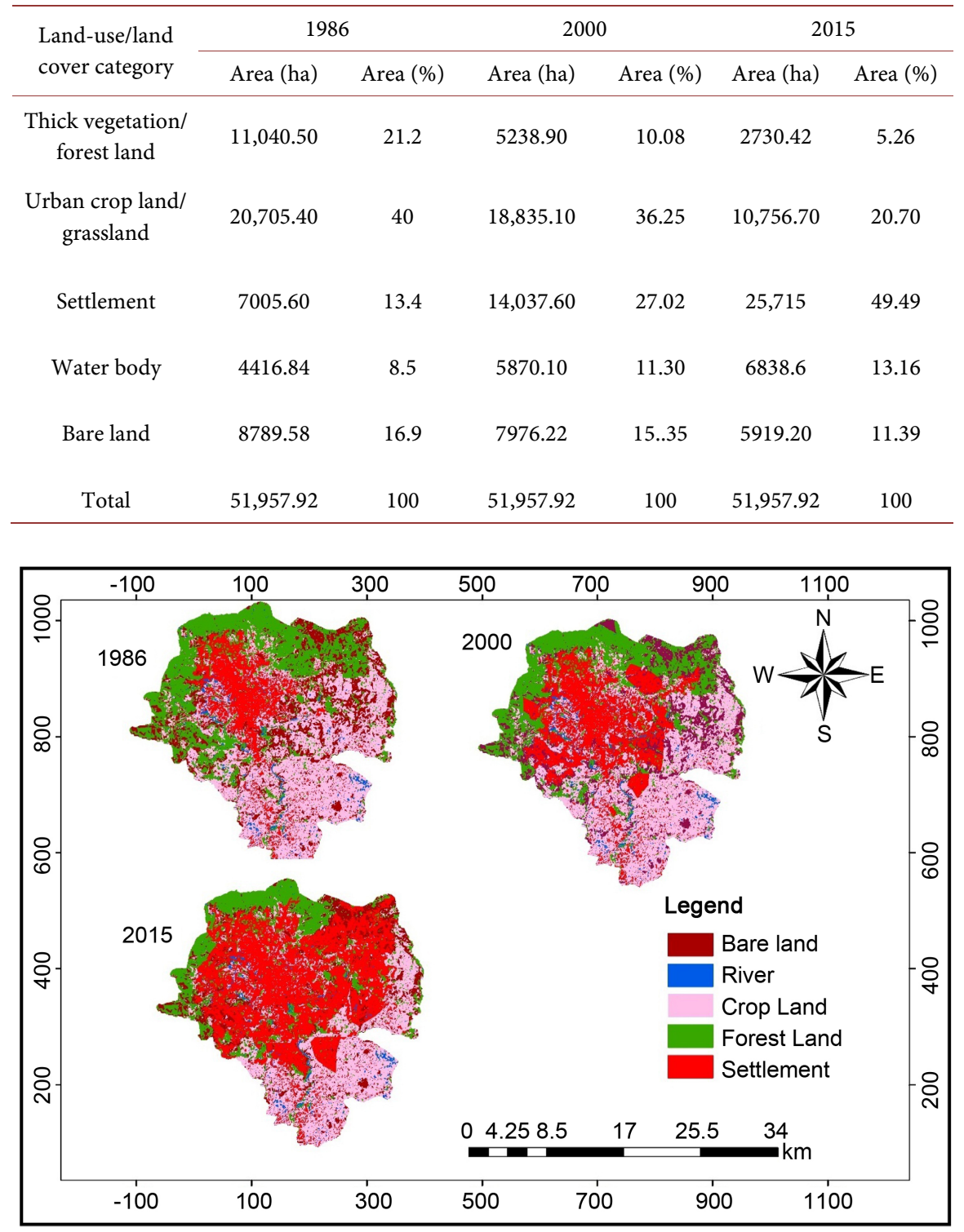

Figure 3. Land-use/land-cover change maps for the years 1986, 2000 and 2015.

was $20,705.40$ ha in 1986 , which declined to $18,835.10$ ha and $10,756.7$ ha in 2000 and 2015, respectively. On the other hand, water body has increased from 4416.84 ha in 1986 to 5870.1 ha in 2000 and to 6836.6 ha in 2015. Settlement area had the highest increase from the initial estimate of 7005.60 ha in 1986. The extent has increased to $14,037.6$ ha in 2000 and to 25,715 ha in 2015. This was the most dynamic land-cover in Addis Ababa, which got extended year after year. The extent of bareland showed slight decline from 8789.58 ha to $7976.22 \mathrm{ha}$ and to 5919.2 ha under classification of the years 1986, 2000 and 2015, respectively. The overall accuracy for land-use/land-cover was $88.80 \%$ in $1986,85 \%$ for 2000 , and $84.00 \%$ for 2015 . Overall land-use/land-cover changes are given in Table 3.

Figure 4 shows the information derived from landsat images. The shades of 
Table 3. Assessment of changes of land-use patterns during 1986-2015.

\begin{tabular}{|c|c|c|c|c|c|c|}
\hline \multirow{4}{*}{$\begin{array}{l}\text { Land-use/ } \\
\text { land-cover } \\
\text { category }\end{array}$} & \multicolumn{6}{|c|}{ Changes during 1986-2015 } \\
\hline & \multicolumn{3}{|c|}{$1986-2000$} & \multicolumn{3}{|c|}{ 2001-2015 } \\
\hline & \multicolumn{2}{|c|}{ Extent } & \multirow{2}{*}{$\begin{array}{c}\text { Rate } \\
\text { (ha/year) }\end{array}$} & \multicolumn{2}{|c|}{ Extent } & \multirow{2}{*}{$\begin{array}{c}\text { Rate } \\
\text { (ha/year) }\end{array}$} \\
\hline & (ha) & (\%) & & (ha) & (\%) & \\
\hline $\begin{array}{c}\text { Thick } \\
\text { vegetation/forest } \\
\text { land }\end{array}$ & -5801.6 & -11.17 & -386.77 & -2508.48 & -4.83 & -167.23 \\
\hline $\begin{array}{c}\text { Urban crop } \\
\text { land/grass land }\end{array}$ & -1870.5 & -3.59 & -124.69 & -8078.4 & -15.55 & -538.56 \\
\hline Settlement & 7032 & 13.53 & 468.8 & $11,677.4$ & 22.47 & 778.49 \\
\hline Bare land & -813.36 & -1.57 & -54.22 & -2057.02 & -3.96 & -137.13 \\
\hline Water body & 1453.26 & 2.80 & 96.88 & 966.5 & 1.86 & 64.43 \\
\hline
\end{tabular}

Note: Annual Rate of Change (ha/year) = (\% of recent land-use/land-cover change-\% of Previous landuse/land-cover change) $/ 100 *$ \# of Study years (15 no of years).

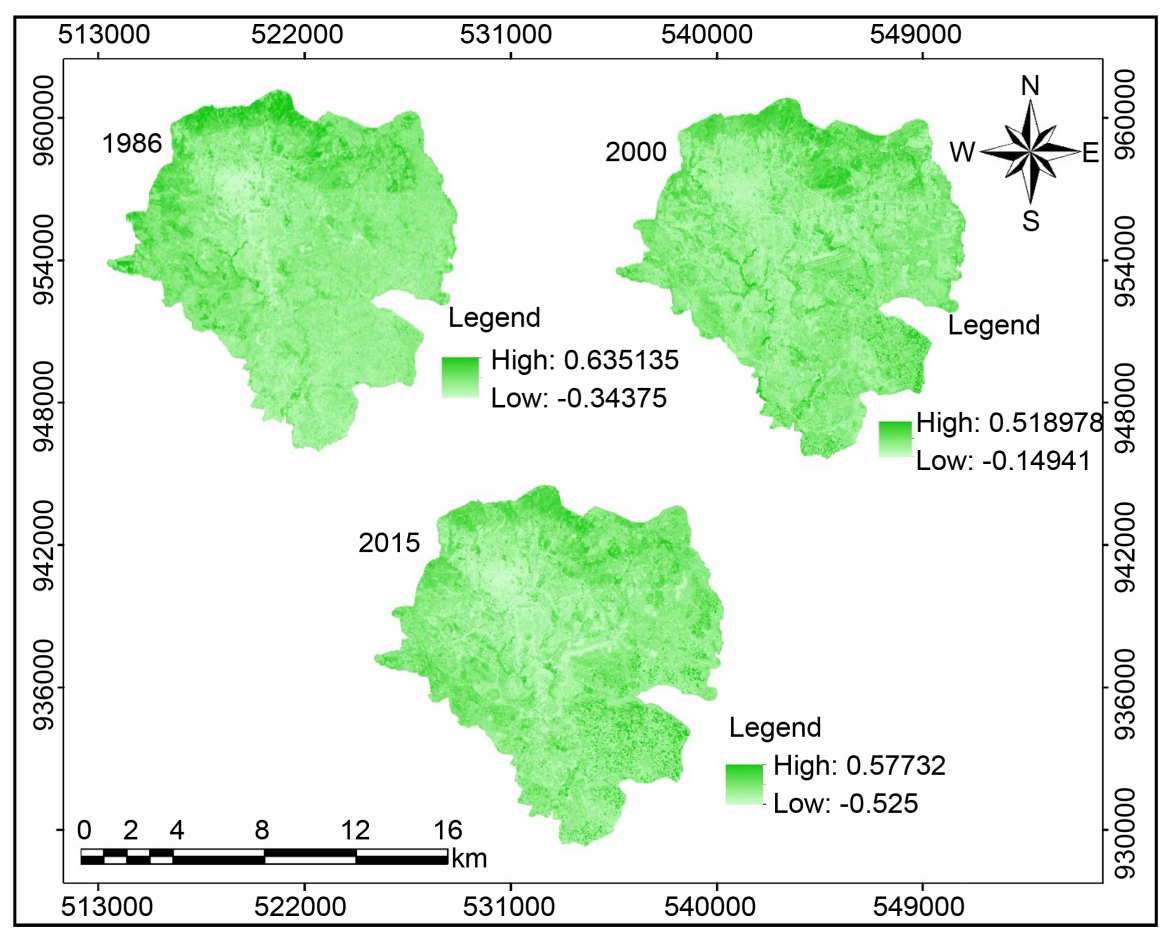

Figure 4. Normalized difference vegetation index maps for the years 1986, 2000 and 2015.

white represent man-made surfaces (concrete, roofs and roads) and water bodies. Light green represents grassy fields and dark green represents tree covered areas. The pixel values of $1986 \mathrm{NDVI}$ image ranged from around -0.34 for not very vegetated surfaces to values of 0.63 for vegetated surfaces. For 2000, the pixel values for the NDVI images ranged from -0.14 for not very vegetated surfaces to 0.51 for vegetated surfaces. For 2015, the pixel values for the NDVI image ranged from -0.52 for none and not very vegetated surfaces to 0.57 for vegetated surfaces. 
Green area distribution patterns in Addis Ababa city are shown in Figure 5 and Figure 6. Yeka and Gulele sub-cities have only about $0.005 \%$ of green area, Akaki-Kality sub-city, Nifassilk-Lafto and Bole have only less than $0.002 \%$ green area. Arada Kirkose and Lideta sub-cites hold too low green areas and Addis Ketema sub-city has almost no vegetation cover while Kolfe Keranio has $0.03 \%$ green area.

Population density in Addis Ababa city in relation to that of the ten sub-cities indicates that the central region is the densest. Addis Ketema with $>350$ people/ ha is the most populated region in Addis Ababa. Arada and Lideta sub-cites have 300 people/ha, while the Akaki-Kality, Yeka and Bole sub-cities have $<17$ people/

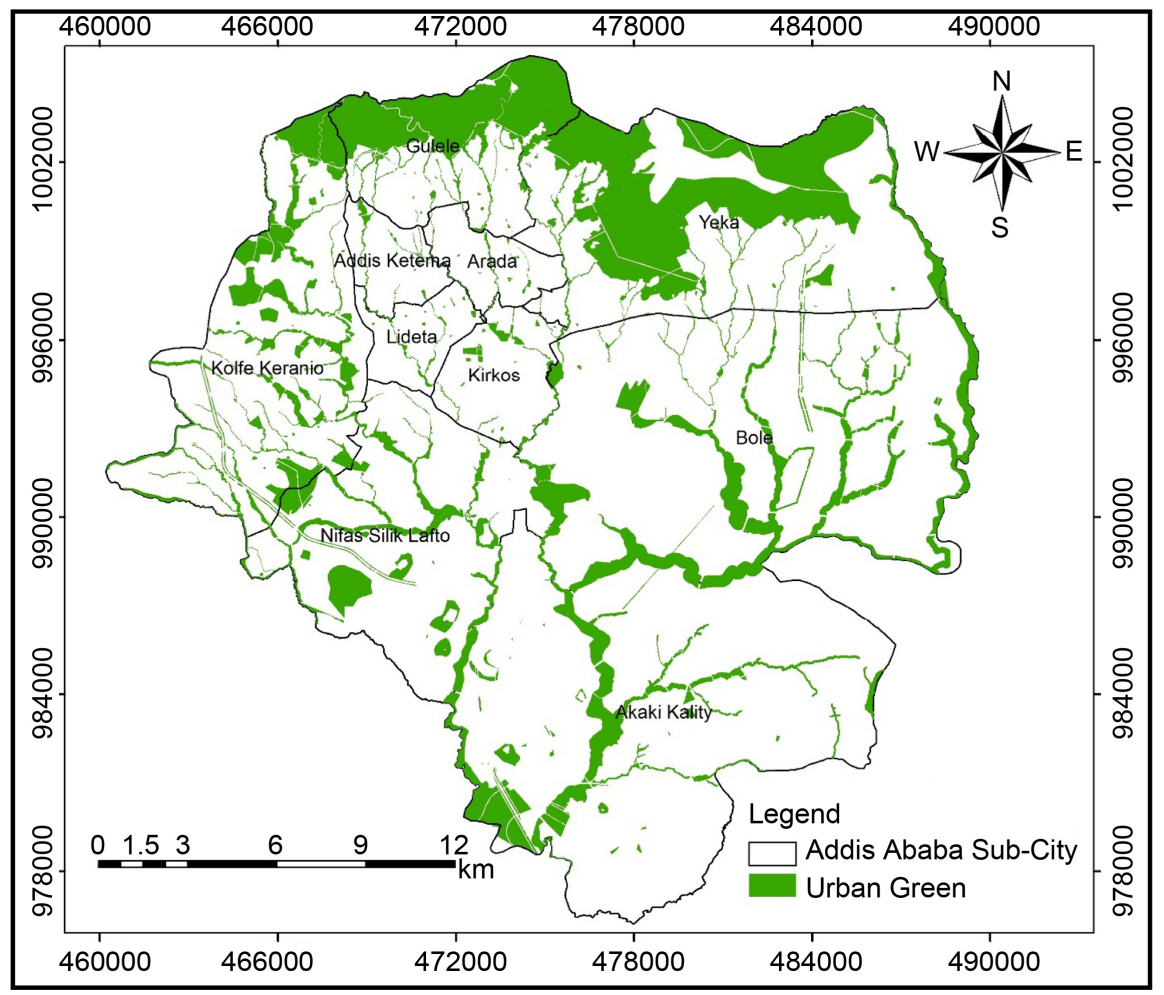

Figure 5. Map of urban green space in Addis Addis Ababa (2015).

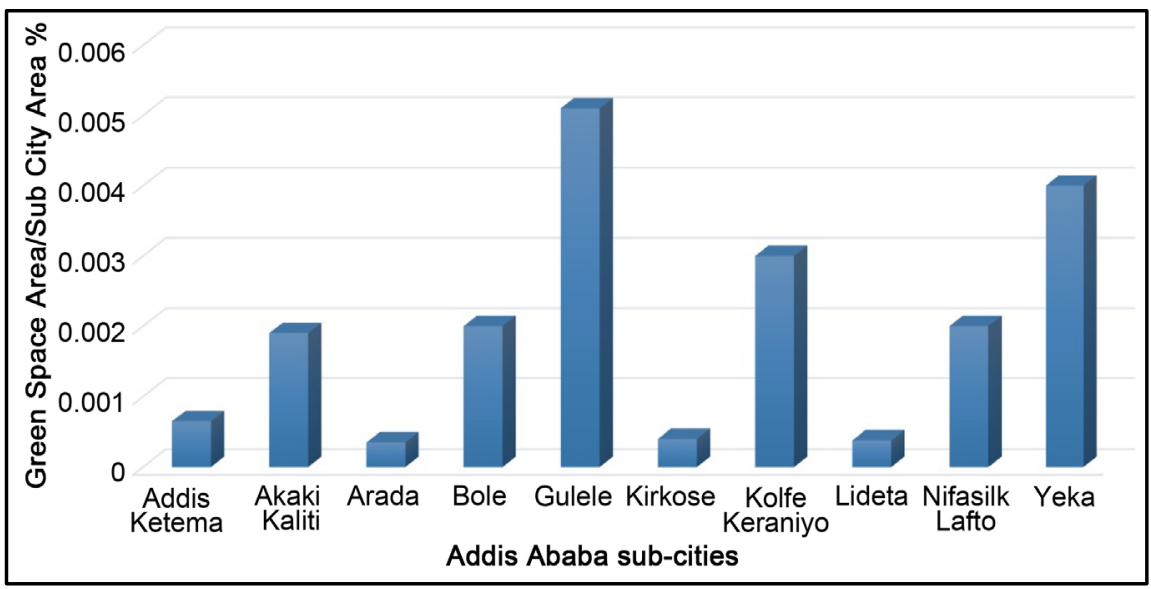

Figure 6. Comparison of urban green space in 10 sub-cities of Addis Ababa. 
ha. There is a general increase of surface temperature in the impervious surfaces (building, concreat and asphalt) in comparison with vegetated areas. Maximum average surface temperature recorded was $36.79^{\circ} \mathrm{C}$ and minimum was $17.40^{\circ} \mathrm{C}$. Based on zonal mean statistics, the surface temperature in Akaki-Kality and Bole sub-city was $29^{\circ} \mathrm{C}$, followed by Addis-Ketema, Arada, Kirkose, Liedeta and Nifase-Silke $\left(28^{\circ} \mathrm{C}\right)$, Yeka $\left(27^{\circ} \mathrm{C}\right)$ and Kolfe $\left(26^{\circ} \mathrm{C}\right)$, respectively, while Gulele sub-city experienced the lowest surface temperature $\left(24^{\circ} \mathrm{C}\right)$ in Addis Ababa.

Greenhouse gas emission data are shown in Figure 7. Concentration of greenhouse gas emission was high associated in industrial and residential areas and in major roads. Based on this, the maximum greenhouse gas emission recorded was 1.41 mega tone and the minimum was 0.25 mega tone. Based on the zonal mean statistics, Akaki Kality sub-city was the most polluted (0.24 mega tone), followed by Addis-Ketema and Lideta ( 0.21 mega tone), Kirkose (0.14 mega tone) Gulele (0.04 mega tone), Kolfe Keranio and Yeka (0.03 mega tone), and Bole, Nifasi-Silke and Akaki-Kality (0.02 mega tone).

\subsection{Overlay Model}

Based on weighted overlay analysis, there was a need to have a universal integration result of the five parameters (land-use/land-cover, population density, surface temperature, greenhouse gas emission and built-up density) to sum up based on the weighting (Table 4 and Table 5) and to isolate the hotspot areas of environmental deterioration the risk-map generated (Figure 8) reclassify as most risk, more risk, risk, marginal and least risk. Based on this classification Addis Ketema belongs its between most risk, Arada more risk, Lideta more risk, Kirkose within risk and Gulele among marginal and least risk and Kolfe, Yeka, Nifas Silke, Bole and Akaki Kality sub-cities belong to least risk. The consistency ratio $(\mathrm{CR})$ indicates the probability that the matrix ratings were randomly generated so that matrices with $\mathrm{CR}$ ratings greater than 0.10 should be reevaluated.

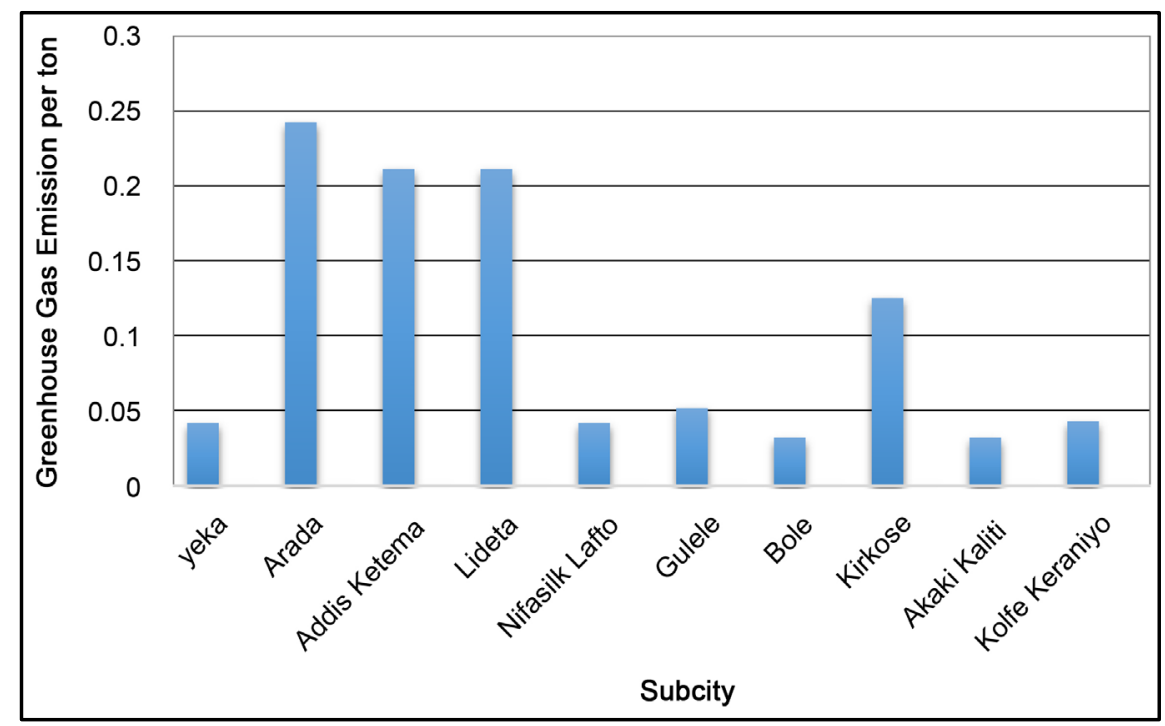

Figure 7. Comparison of greenhouse gas emission in the ten sub-cities of Addis Ababa. 
Table 4. Derived factor maps and ranking.

\begin{tabular}{|c|c|c|c|c|c|c|c|}
\hline \multirow{2}{*}{ Parameters } & \multirow{2}{*}{ Criteria } & \multirow{2}{*}{ Unit } & \multicolumn{5}{|c|}{ Urban environmental quality indicator rating } \\
\hline & & & High & Moderate & Marginal & Not & suitable \\
\hline \multirow[t]{2}{*}{ Land-cover } & $\mathrm{LU} / \mathrm{LC}$ & Class & $\begin{array}{c}\text { Forest/ } \\
\text { vegetation } \\
\text { land }\end{array}$ & $\begin{array}{c}\text { Crop/land/grass } \\
\text { land }\end{array}$ & Water body & $\begin{array}{l}\text { Bare } \\
\text { land }\end{array}$ & Settlement \\
\hline & NDVI & Value & $0.22-0.52$ & $0.15-0.22$ & $0.09-0.15$ & -0.15 & -0.01 \\
\hline $\begin{array}{l}\text { Existing } \\
\text { LU/LC }\end{array}$ & $\begin{array}{c}\text { Built up } \\
\text { area }\end{array}$ & Density & $0.05-0.08$ & $0.08-0.09$ & $0.09-0.14$ & $>0.14$ & \\
\hline Urban heat & $\begin{array}{c}\text { Surface } \\
\text { temperature }\end{array}$ & ${ }^{\circ} \mathrm{C}$ & $17-24$ & $24-27$ & $27-29$ & $>29$ & \\
\hline Population & $\begin{array}{l}\text { Population } \\
\text { size }\end{array}$ & Density & $0.0018-0.003$ & $0.003-0.005$ & $0.005-0.006$ & $>0.006$ & \\
\hline $\begin{array}{c}\text { Green house } \\
\text { gas }\end{array}$ & $\begin{array}{c}\text { Carbon } \\
\text { emission }\end{array}$ & Tone & $0.02-0.03$ & $0.03-0.14$ & $0.14-0.23$ & $>0.23$ & \\
\hline
\end{tabular}

Table 5. Derived factor maps weight.

\begin{tabular}{ccc}
\hline No & Criteria & Weight \% \\
\hline 1 & Land-use/land-cover & 24 \\
2 & Built up density & 17 \\
3 & Surface temperature & 16 \\
4 & Population density & 21 \\
5 & Green house gas emission & 22 \\
\hline
\end{tabular}

Consistency Ratio (CR) is 0.02 .

However, in this study the CR calculated as 0.02 is acceptable. Based on the urban environmental quality indicator rating (Table 5), sub-cities with fewer green spaces, over polluted, high heat accumulation, high greenhouse gas emission and densely built-up areas were identified as critical areas and those with high vegetation, low greenhouse gas emission, low heat island, low built-up area and sparsely populated locations as environmentally safe areas (Figure 8). Based on these results, sub-cities Arada and Addis Ketema were in the category in between most and more critical, Kirkose and Lideta sub-cities were within critical and marginal and Kolfe, Gulele, Yeka, Nifas Silke, Bole and Akaki Kality were least critical.

\section{Discussion}

During the present study, a comparison was made between the increase in impervious surface against the reduction in greenness in Addis Ababa city areas that might signify deterioration in the environmental quality of this African city. Vegetation, crop land/grassland, bare land, settlement and water bodies were either increased or decreased in extent in different rates during 1986-2015 in 


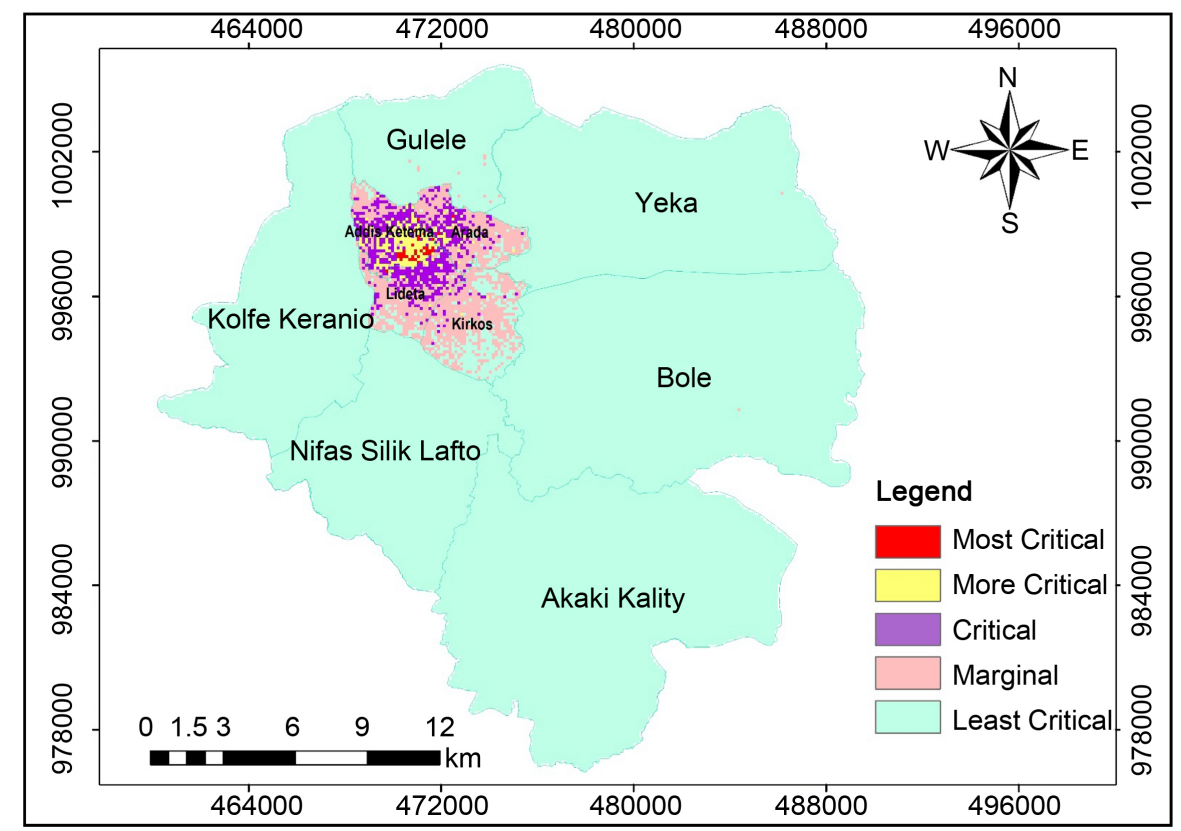

Figure 8. Environmental quality map of Addis Ababa city.

Addis Ababa city area. Greenness of the area serves as a means of urban environmental quality [7] [3] [17]. Information on green area in cities is important for maintaining urban environmental quality. Vegetation is very useful in filtering air, water and sunlight, cooling urban heat, recycling pollutants, moderating local urban climate and providing recreational areas for the people. The ecological functions of vegetation cover in urban parks may filter up to $85 \%$ of the air pollutants [9] [18].

Settlement areas increased from the initial estimate of 7005.60 ha in 1986 to 25,715.0 ha in 2015 with the change rate of 468.8 ha/year during 1986-2000 and 778.49 ha/year during 2001-2015. This was the most dynamic land-cover change observed in Addis Ababa city area, the cause of which is none other than urbanization and rapid population growth in the recent past. Unbalanced and uncontrolled urbanization lead to environmental degradation in the quality of urban life [19]. The extent of bareland declined slightly from 8789.58 ha 7976.22 and 5919.2 of the total area under the classification of the year 1986, 2000 and 2015 , respectively. This is mainly due to afforestation and rehabilitation conservation programmes. Normalized Difference Vegetation Index is a spectral index that takes into account the amount of infrared rays reflected by plants [20] [21]. Green plants absorb solar radiation, as a source of energy in the process of photosynthesis. The reason for the relationship of NDVI to vegetation is due to the property of green leaves to reflect $20 \%$ or less in 0.5 to 0.7 microrange (green to red) and about $60 \%$ in 0.7 to 1.3 microrange (near-infrared). Normalized Difference Vegetation Index itself varies between -1.0 and +1.0 . Negative values of NDVI (values approaching -1) correspond to deep water. Values close to zero ( -0.1 to 0.1$)$ correspond to bare land areas of rock and sand. The nature and extent of these changes show variations across time and space. Changes attributed to socio-economic and environmental parameters reflect a host of other factors. 
In Addis Ababa city, Yeka and Gulele sub-cities contains about $0.005 \%$ of green area, while Kolfe-Keranio cover $0.03 \%$ green area and Akaki-Kality, Nifassilk-Lafto and Bole contain $<0.002 \%$ green area. Other inner areas in the city such as Arada Kirkose and Lideta hold too low green areas and Addis-Ketema sub-city contains almost zero or no vegetation cover. Green space in Kirkose, Addis-Ketema, Lideta, Arad and kolfe having least green space $\left(4.8 \times 10^{-6}\right.$ square meter) are the poorest. Gulele and Yeka have $<1.5 \times 10^{-5}$ square meter vegetation area. The suggested standard of green area for cities is 7 to 12 square meters [22]. This indicates that none of Addis Ababa sub-cities contains the required extent of green area to maintain environmental quality. Over all, the results point to a decline in vegetated areas in Addis Ababa city area, and an increase in settlements, cropland, bare land, population explosion, as well as greenhouse gas emission, which act as threat to the environment of the city. There is a need to have a universal integration of the five parameters analyzed. Overall housing density is a more important negative predictor of the extent of green space and tree cover [23]. Weighted overlay methodologies can also be customized for reclassification, and map algebra techniques expand the ability of spatial analyses. The accuracy of the study can be enhanced by using high resolution satellite imagery. Not only the urban environmental quality, but also other subjects important for ecological and environmental impact analysis such as air, water, and noise pollution limitations can also be determined using RS and GIS integration. Environmental risk and quality map are also source of data for city and regional planners.

\section{Conclusion}

In the light of the present findings, the practical use of geospatial approach involving natural and census data, GIS and remote sensing in tracking urban environment quality change stands appropriate for sustainable environmental planning, considering the little efforts in the past to assess urban environmental quality. Integrated data analysis using remotely sensed satellite imagery and GIS modeling facilitated the analysis of the spatial distribution of environmental changes involving land-use/land-cover classification changes from time to time. Results of this study can influence policy assessments and assist local governments and environmental agencies in monitoring Urban Environmental Quality (UEQ). The UEQ models established in this paper can be applied to assist urban planners not only to evaluate the city's current UEQ condition, but also to devise efficient development polices to construct a more desirable future UEQ environment at the national level. Land-use planners and policy makers can thus make decisions towards a more sustainable city featuring green areas, which correspond well as a key factor in determining a city's UEQ condition.

\section{Acknowledgements}

We are grateful to the School of Earth Sciences, Addis Ababa University for access to the laboratory facilities and support for this research programme. We 
are also thankful to the Central Statics Agency and Addis Ababa Environmental Protection Agency, for their collaboration in delivering valuable data used in this study. We also thank the anonymous reviewers for their valuable comments to improve this manuscript.

\section{References}

[1] Jim, C.Y. and Chen, W.Y. (2008) Assessing the Ecosystem Service of Air Pollutant Removal by Urban Trees in Guangzhou (China). Journal of Environmental Management, 88, 665-676.

[2] Tongliga, B., Xueming, L., Jing, Z., Yingjia, Z. and Shenzhen, T. (2016) Assessing the Distribution of Urban Green Spaces and Its Anisotropic Cooling Distance on Urban Heat Island Pattern in Baotou, China. International Journal of Geo-Information, 5, 12.

[3] Opeyemi, A. and Trina, W. (2014) Potential Application of Change in Urban Green Space as an Indicator of Urban Environmental Quality Change. Universal Journal of Geoscience, 2, 222-228.

[4] Low, N., Gleeson, B., Green, R. and Radovic, D. (2007) The Green City, Sustainable Homes, Sustainable Suburbs. Rutledge, London, 80-101.

[5] Aravadinou, D. and Evmorfoulou, A. (1999) Planted Lofts, an Indirect Way for the Reintroduction of Vegetation into the Built-In Environment. Ktirio Technical Magazine, No. 102. (In Greek)

[6] Faryadi, S. and Taheri, S. (2009) Interconnections of Urban Green Spaces and Environmental Quality of Tehran. International Journal Environmental Research, 3, 199-208.

[7] Rafiee, R., Salman Mahiny, A. and Khorasani, N. (2009) Assessment of Changes in Urban Green Spaces of Mashad City Using Satellite Data. International Journal of Applied Earth Observation and Geoinformation, 11, 431-438.

[8] Christian, E. and Ugoyibo, O. (2013) Mapping Enugu Cities Urban Heat Island. International Journal of Environmental Protection and Policy, 1, 50-58.

[9] Liang, B. and Weng, Q. (2011) Assessing Urban Environmental Quality Change of Indianapolis, United States, by the Remote Sensing and GIS Integration. IEEE Journal of Selected Topics in Applied Earth Observations and Remote Sensing, 4, 43-55. https://doi.org/10.1109/JSTARS.2010.2060316

[10] Mehmet, C. (2015) Using GIS Analysis to Assess Urban Green Space in Terms of Accessibility: Case Study in Kutahya. International Journal of Sustainable Development \& World Ecology, 22, 420-424.

[11] Akanbi, A., Kumar, S. and Fidelis, U. (2013) Application of Remote Sensing, GIS and GPS for Efficient Urban Management Plan-A Case Study of Part of Hyderabad City. Novus International Journal of Engineering and Technology, 2, 1-14.

[12] Cromley, E. (2013) Geospatial Method in Health Geographic Research. Department of Physical Geography and Quaternary Geology, Stockholm University, Stockholm.

[13] CSA (2015) Central Statistical Agency of Ethiopia, Annual Report. http://www.csa.gov.et/index.php/2013-02-20-13-43-35/national-statistics-abstract/1 41-population

[14] Campbell, J.B. (1987) Introduction to Remote Sensing. The Guilford Press, New York.

[15] Lillesand, T., Keifer, R.W. and Chipman, J. (2007) Remote Sensing and Image Interpretation. 6th Edition, John Wiley \& Sons Inc., New Delhi. 
[16] Esri (2013) International User Conference. San Diego.

[17] Debbage, N. and Shepherd, J.M. (2015) The Urban Heat Island Effect and City Contiguity. Computers, Environment and Urban Systems, 54, 181-194.

[18] Bolund, P. and Hunhammar, S. (1999) Ecosystem Services in Urban Areas. Ecological Economics, 29, 293-301.

[19] Saied, P., Ahmad, S., Heshmi, A. and Hussain, J. (2005) Greenery (Green Space) Percentage Estimation Using Band Ratio, NDVI From Landsat Enhanced Thematic Mapper (ETM-2002) and an Application of Geographic Information System (GIS) Techniques, Dezful-Andimeshk, Khuzestan South-West Iran. 8th International Seminar on Map India, New Delhi, 7-9 February 2005.

[20] Simmon, R. (1980) Normalized Difference Vegetation Index (NDVI). Analysis for Forestry and Crop Management. 41-48.

[21] Agyepong, A.O. and Nhamo, G. (2016) Green Procurement in South Africa: Perspectives on Legislative Provisions in Metropolitan Municipalities. Environment Development and Sustainability, 1-18.

[22] Zoeshtiagh, S. (1998) The Abstract of Tehran Comprehensive Plan: Conservation and Redevelopment Plan; 1992, Certified by the Higher Consulate of Urban Planning and Architecture of Iran. The Company of Urban Processing and Planning, Tehran, 20-31.

[23] Davies, M., Steadman, P. and Oreszczyn, T. (2008) Strategies for the Modification of the Urban Climate and the Consequent Impact on Building Energy Use. Energy Policy, 36, 4548-4551.

\section{Submit or recommend next manuscript to SCIRP and we will provide best} service for you:

Accepting pre-submission inquiries through Email, Facebook, LinkedIn, Twitter, etc. A wide selection of journals (inclusive of 9 subjects, more than 200 journals)

Providing 24-hour high-quality service

User-friendly online submission system

Fair and swift peer-review system

Efficient typesetting and proofreading procedure

Display of the result of downloads and visits, as well as the number of cited articles

Maximum dissemination of your research work

Submit your manuscript at: http://papersubmission.scirp.org/

Or contact jgis@scirp.org 